\title{
EDITORIAL \\ Stigma in psychiatry seen through the lens of sexuality and gender
}

\author{
Michael King $\odot$
}

Primary Care Psychiatry, Division of Psychiatry, Faculty of Brain Sciences, and PRIMENT Clinical Trials Unit, University College London, B Wing, 6th Floor, Maple House, 149 Tottenham Court Road, London W1T 7NF, UK.

Email: michael.king@ucl.ac.uk

Conflicts of interest None.

Keywords. Stigma and discrimination; homosexuality; transgender; psychiatry; psychology.

First received 4 Apr 2018 Final revision 11 Apr 2019

Accepted 16 May 2019

doi:10.1192/bji.2019.12

(c) The Author 2019. This is an Open Access article, distributed under the terms of the Creative Commons Attribution-

NonCommercial-NoDerivatives licence (http://creativecommons. (licenses/by-nc-nd/4.0/), which permits non-commercial re-use, distribution, and reproduction in any medium, provided the original work is unaltered and is properly cited. The written permission of Cambridge University Press must be obtained for comPress must be obtained for commercial re-use or in order to create a derivative work.
The history of psychiatry and homosexuality illuminates how stigma develops in the professions, how it is linked to cultural values and religious attitudes and how it affects patients. Homosexuality was medicalised as a disorder in the late 19th century and this led to treatments to change it. Same-gender contacts between men were decriminalised in many countries in the 1960 s and 1970 s, but as recently as the 1980 s $-30 \%$ of doctors in the USA did not think that gay students should be admitted to medical school and $40 \%$ would not allow gay doctors to specialise in paediatrics or psychiatry. Lesbians and gay men were effectively debarred from training in the main psychoanalytical schools in the USA and the UK. Although mainstream psychological treatments to make gay and bisexual people heterosexual fell into disrepute in the 1980 s, so-called conversion or reparative treatments took their place and are still practised today. Transgender people have been the target of similar disapproval and attitudes towards them have been even slower to change than those towards lesbians and gay men. This stigma had consequences on the health, well-being and social inclusion of those who were lesbian, gay, bisexual and transgender (LGBT). This history suggests we need to examine where psychiatry and psychology are making similar mistakes today.

The first goal of the World Psychiatric Association's Action Plan for 2014-2017 was to enhance the reputation of psychiatry and eliminate stigma, discrimination practices and negative attitudes across the world to mental illness (http://www.wpanet. org/detail.php?section_id=25\&content_id=1132). However, it is sometimes forgotten that mental health professionals may hold similar stigmatising attitudes as those held by the general public. Negative attitudes to mental illness start early in medical students and trainee doctors, and professionals' attitudes such as these influence public attitudes.

\section{The lens of sexual orientation}

In most societies same-gender behaviour was traditionally regarded as unnatural and morally perverse. It was only in the late 19 th century that it came to be regarded in terms of biology and illness. Sexologists such as Magnus Hirschfeld, writing in the early 20th century, attempted to recast same-gender behaviour in scientific terms. Although their intentions were to encourage the idea of same-gender behaviour as a natural human phenomenon, this often led to attempts to diagnose it as a disorder and treat it. This is seen in the muddle that the diagnosis of homosexuality became, beginning in the DSM-I (1952) and continuing until it was finally removed in the DSM-III-R (1987). Designation of a human characteristic and behaviour as pathological was encouraged by attitudes in society to homosexuality, but it also contributed to those attitudes. The tide finally turned in the UK in the early 1950s with the formation of the Departmental Committee on Homosexual Offences and Prostitution, which was led by Lord Wolfenden. Their remit was to review the then-current attitudes to homosexuality at all levels in English society and to determine whether legislative change was needed - in particular whether same-gender contacts between men should remain a criminal offence. To do so, they took evidence from the British Medical Association (BMA). The BMA's memorandum of evidence was condemning in its moral and medical tone (BMA, 1955). The British doctors' organisation considered that homosexual 'habits' arose from a defective home life and looseliving parents, and was encouraged by seduction or imitation. Recommendations included segregation of homosexual men from mainstream society, physical treatments to cure the disorder and a strong steer that homosexuals not be employed in 'sensitive' occupations such as the Church of England, the civil service or the armed forces. Despite such negative reports, the Wolfenden Committee recommended change in 1957 and this was enacted by parliamentary legislation to decriminalise same-gender contacts between men in 1967. Further legislation followed, including changes to the age of consent for same-gender relationships (1994, 1999 and 2000), the introduction of civil partnerships (2004), the Equality Act (2010) and most recently the Marriage (Same Sex Couples) Act (2013).

Unfortunately, the attitudes of mental health professionals were much slower to change. Studies in the 1970s and 1980s revealed that family doctors and psychiatrists in Western countries held negative attitudes towards same-gender desire and behaviour. Results of a USA study in 1986 showed that $30 \%$ of doctors would not 
admit highly qualified gay students to medical school and $40 \%$ would not allow gay doctors to specialise in paediatrics or psychiatry (Mathews et al, 1986). The attitudes of doctors were no further ahead than those of the general population. Despite changes to international diagnostic glossaries from the 1970s, it was still considered unacceptable for psychiatrists or psychologists to be openly gay or lesbian. Attitudes in the UK were less negative but hardly ahead of the general population (Bhugra \& King, 1989; Morris, 1973). There is well-documented evidence that homosexual or transgender candidates were considered unfit to practice and were thus denied entry to psychoanalytical training or they suffered discrimination when they revealed their sexuality as practising analysts (Isay, 1997).

\section{The lens of gender}

Transgender people have been the recipients of similar moral and medical disapproval. Transgender and gender non-conforming (TGNC) people are those whose gender identity and/or gender role do not accord with the gender recorded at birth. Not all people who are TGNC, however, self-identify as transgender: they may regard themselves as gender fluid, gender nonconforming or non-binary. A similar evolution is underway in the current generation of younger people who do not identify with the traditional groupings of heterosexual, lesbian, gay or bisexual to describe their sexual orientation. These changes show how more natural groups arise when psychiatric labels are discarded and people feel free to self-identify in new ways.

Gender identity disorder was the umbrella term used in the ICD-10 (1992) and in the DSM-IV (1994) to diagnose people who are TGNC. These diagnostic labels not only defined a person who was TGNC as disordered, but also meant that mental health professionals controlled access to the process of transition. Psychiatric assessments were said to ensure that transition is offered to those people most likely to benefit. Ultimately, however, it is controlling and defined by what is now considered an outdated conception of psychiatric pathology. Thus the notion that people who are transgender have a mental disorder is gradually being dropped from these two major psychiatric diagnostic classifications. Recent drafts of the ICD-11 (due for full adoption in 2022) have removed reference to disorders of gender identity from the mental health section. A new term 'gender incongruence' now appears on a chapter on sexual health. The DSM-5 (2013) retains a diagnosis of gender dysphoria. Both of these terms are being retained as a way of ensuring that people who are transgender might access transition-related health and social treatments.

As in the case of sexual orientation, most of the history of psychiatric practice with people who are TGNC has been imbued with the conviction that transgenderism or gender dysphoria are mental health diagnoses. Doctors were often ill-informed and discriminating, which led to distress and exclusion of people who were TGNC. However, attitudes and practice have improved somewhat in recent years, at least in the USA (Ali et al, 2016).

\section{Psychological treatments for homosexuality and so-called gender identity disorders}

The most obvious stigma generated by psychiatry in the field of sexuality was the development of psychological treatments that aimed to make homosexual people heterosexual. Psychoanalysis from the 1920 s to the 1980 s embraced the challenge of correcting the unconscious wound that led to homosexuality (Bieber et al, 1962). But it was behaviourism that led the way with the development of aversion therapy in the 1960s (King \& Bartlett, 1999). On 12 February 1965, Time magazine lead with an article claiming that 'Homosexuals Can Be Cured'. Undoubtedly, such prominence in the media had a major effect on gay and lesbian people and their families. However, the evidence did not keep up with the development of the treatments and they fell into disrepute by the 1980s. This was partly because of lack of evidence of efficacy, but also as a result of cultural and moral objections to the practice. Unfortunately, so-called reparative therapies soon took their place. These were treatments or counselling designed to change or move a person's sexual orientation from homosexual or bisexual to heterosexual. The term reparative therapy was a revealing choice. Both the psychoanalytical and the behaviourist literature regarded homosexuals as damaged heterosexuals who - either because of parental attitudes or faulty learning - had strayed from the normal path of development. Although strictly phrased within a psychoanalytical framework, the process of the new reparative therapies often included an element of spirituality. They arose in many religious settings in the USA but were soon promulgated throughout the rest of the Western world. The theory went that homosexuality arose from the 'an incomplete bond and resultant identification with the same-gender parent, which is then symbolically repaired in psychotherapy' (Nicolosi, 1997). Thus psychotherapy involved the encouragement of so-called masculine activities, learning new male role models, becoming more assertive with women through flirting and dating and eventually to engage in heterosexual intercourse and father children. Prayer and attempts at self-control were also involved. The evidence for efficacy relied on anecdotal reports or samples of volunteers often recruited months or years after treatment. It is only in recent years that organisations promulgating reparative therapy have closed down (in some cases apologising to lesbian, gay, bisexual and transgender [LGBT] people and their families) and it has become obvious that such treatments have no grounding in evidence. A well-known psychiatrist Robert Spitzer went so far as to retract the 
findings of his flawed study about conversion therapies (Spitzer, 2003), apologising to those affected (Carey, 2012). Nevertheless, these therapies caused considerable damage to people who are LGBT and their families (Smith et al, 2004). A similar retraction occurred with regard to a paper published in 2006 which claimed that homosexual behaviour was a sin in Islam and that people who are gay need to change (Ahmed, 2006, 2015). Nevertheless, even as late as 2000 evidence showed that a small minority of mental health professionals in the UK were either prepared to undertake conversion therapies or refer people to professionals who could do so. This evidence along with additional evidence of harm from research in the USA led to the first Memorandum of Understanding in the UK between national therapy and health organisations. It was published in 2015 and pointed out the lack of evidence for efficacy and the potential harm of conversion therapies. It has been followed by an update in 2017 to include transgender people.

It is not always easy to discern how conversion therapies for people who are TGNC are practised or the impact they have on those people receiving them. It would appear that specific conversion therapies that aim to persuade people who are TGNC to remove their gender dysphoria and become cis-gender are uncommon (Wright et al, 2018). However, there is evidence that these people encounter barriers to receiving appropriate treatments to enable transition. The evidence on conversion treatments in people who are TGNC is more difficult to disentangle than that for people who are lesbian, gay and bisexual (LGB). It is not always clear from published descriptions of conversion therapies whether they include people who are TGNC. Perhaps more importantly, whereas people who are TGNC may need a diagnosis to access treatments for transition, this is of no relevance to people who are LGB. More evidence about gender identity and transgender youth is needed, particularly how gender dysphoria continues from childhood into adolescence and the impact of interventions for very young people who are transgender.

\section{The consequences of stigmatisation}

People who are LGB are at higher risk for almost all forms of mental disorder, including self-harm and completed suicide, than heterosexuals. Rates of psychological distress and self-harm may be even higher in people who are TGNC and are linked to minority stress (Testa et al, 2017). Although we clearly cannot lay all of this at the door of doctors and mental health professionals, there is little doubt that the attitudes of medicine, psychiatry and psychology towards people who are LGBT contributed to this psychological fallout. When any variation from heterosexuality or gender identities as male or female are regarded as mental disorder, it is difficult for young people to come to terms with their emerging sexuality or gender identity.
Everywhere they turn there is stigma or discrimination, and sadly the most severe may come from their doctors.

There has been a positive shift of public opinion in the past 10-20 years, at least in Europe, North and South America and Australasia. This has meant much greater acceptance of variation both in sexual orientation and gender identity. However, this trend has not occurred in many other regions of the world where repressive legislation regulating same-gender behaviour has been introduced. In 2016, 75 countries continued to criminalise same-gender contacts (Carroll, 2016). The Pew Global Attitudes Surveys has shown that world public opinion is polarised with much lower acceptance in Eastern Europe, the Arab countries and many parts of Africa (Hadler \& Symons, 2018).

Given greater acceptance of sexual variation in the more liberal countries, it was hoped that LGBT mental health would improve. Unfortunately, even recent evidence would suggest that young people continue to suffer from a burden of increased psychological morbidity. Given parental attitudes are also key to the wellbeing of LGBT youth, it may take yet another generation in countries such as the USA and the UK for things to change for the better - at least in Western, liberal societies. Unfortunately, we know much less about how attitudes are changing in less-accepting societies where research is more limited. Many studies have small samples and focus on sexual health (Muller \& Hughes, 2016). Recent evidence suggests that levels of psychiatric morbidity in people who are LGBT are much higher than the general population in southern and eastern Africa, irrespective of the presence of criminalising or protective legislation (Daskilewicz \& Müller, 2018). This suggests that societal stigma is the strongest force that drives mental distress in people who are LGBT.

\section{Lessons for the future}

What have we learned in terms of psychiatry and stigma? Most of all we need mental health professionals to stand apart from current cultural prejudices. A current example where the process has spun into reverse is to be found in Russian society where political and public attitudes to homosexuality have hardened. As they do so, there are signs that Russian medicine is following suit in regarding sexual minority people as mentally disordered (Bartholomew, 2014). This peculiar history of treatment of people who are LGBT impels us to seek out where psychiatry and psychology are making similar mistakes today.

\section{References}

Ahmed M. B. (2006) Homosexuality: an islamic perspective. Journal of the Islamic Medical Association of North America, 38, 27-33.

Ahmed M. B. (2015) Partial retraction: 'homosexuality: an islamic perspective'. Journal of the Islamic Medical Association of North America, 44, 1-3. 
Ali N., Fleisher W. \& Erickson J. (2016) Psychiatrists' and psychiatry residents' attitudes toward transgender people. Academic Psychiatry, 40, 268-273.

Bartholomew R. E. (2014) Beware the medicalisation of deviance in Russia: remembering the lessons of history. Journal of the Royal Society of Medicine, 107, 176-177.

Bhugra D. \& King M. (1989) Controlled comparison of attitudes of psychiatrists, general practitioners, homosexual doctors and homosexual men to male homosexuality. Journal of the Royal Society of Medicine, 82, 603-605.

Bieber I., Dain H. J., Dince P. R., et al (1962) Homosexuality: A Psychoanalytic Study. Basic Books.

British Medical Association (BMA) (1955) Homosexuality and Prostitution. A Memorandum of Evidence Prepared by a Special Committee of the British Medical Association for Submission to the Departmental Committee on Homosexuality and Prostitution. British Medical Association.

Carey B. (2012) Psychiatry Giant Sorry for Backing Gay Cure. The New York Times.

Carroll A. (2016) State sponsored homophobia 2016: a world survey of sexual orientation laws: criminalisation, protection and recognition. International Lesbian, Gay, Bisexual, Trans and Intersex Association (ILGA).

Hadler M. \& Symons J. (2018) World society divided: divergent trends in state responses to sexual minorities and their reflection in public attitudes. Social Forces, 96, 1721-1756.

Isay R. A. (1997) Becoming Gay: The Journey to Self Acceptance. Henry Holt.
King M. \& Bartlett A. (1999) British psychiatry and homosexuality. British Journal of Psychiatry, 175, 106-113.

Mathews W. M. C., Booth M. W., Turner J. D., et al (1986) Physician's attitudes to homosesxuality - Survey of a California County Medical Society. The Western Journal of Medicine, 144, 106-110.

Morris P. A. (1973) Doctors' attitudes to homosexuality. British Journal of Psychiatry, 122, 435-436.

Müller A. \& Daskilewicz K. (2018) Mental health among lesbian, gay, bisexual, transgender and intersex people in East and Southern Africa. European Journal of Public Health, 28(suppl_4), 270-271.

Muller A. \& Hughes T. L. (2016) Making the invisible visible: a systematic review of sexual minority women's health in Southern Africa. BMC Public Health, 16, 307.

Nicolosi J. (1997) Reparative Therapy of the Male Homosexual: A New Clinical Approach. Rowan \& Littlefield.

Smith G., Bartlett A. \& King M. (2004) Treatments of homosexuality in Britain since the 1950s-an oral history: the experience of patients. $B M J, 328,427$.

Spitzer R. L. (2003) Can some gay men and lesbians change their sexual orientation? 200 participants reporting a change from homosexual to heterosexual orientation. Archives of Sexual Behaviour, 32, 403-417.

Testa R. J., Michaels M. S., Bliss W., et al (2017) Suicidal ideation in transgender people: gender minority stress and interpersonal theory factors. Journal of Abnormal Psychology, 126, 125-136.

Wright T., Candy B. \& King M. (2018) Conversion therapies and barriers to transition related healthcare in transgender people: a narrative systematic review. BMJ Open, 8, e022425. 